Article

\title{
Thermo-Mechanical Finite Element Modeling of the Laser Treatment of Titanium Cold-Sprayed Coatings
}

\author{
Felice Rubino ${ }^{1}$, Antonello Astarita ${ }^{2}$ (i) and Pierpaolo Carlone ${ }^{1, *(1)}$ \\ 1 Department of Industrial Engineering, University of Salerno, Via Giovanni Paolo II 132, Fisciano, \\ Salerno 84084, Italy; frubino@unisa.it \\ 2 Department of Chemical, Materials and Industrial Production Engineering, University of Naples "Federico II", \\ P. Tecchio 80, Naples 80125, Italy; antonello.astarita@unina.it \\ * Correspondence: pcarlone@unisa.it
}

Received: 11 May 2018; Accepted: 8 June 2018; Published: 12 June 2018 updates

\begin{abstract}
This paper implements a thermo-mechanical model to simulate the laser treatment effects on a cold-sprayed titanium coating and aluminum substrate. The thermo-mechanical finite element model considers the transient temperature field due to the laser source and applied boundary conditions, using them as input loads for the subsequent stress-strain analysis. Numerical outcomes highlighted the relevance of thermal gradients and the presence of thermally-induced stress-strain fields responsible for promoting damage in the coating.
\end{abstract}

Keywords: cold spray; titanium; laser surface treatment; thermo-mechanical modeling

\section{Introduction}

Deposition of titanium using cold spray technology is experiencing considerable interest in recent years as an effective solution to develop titanium deposits as a barrier coating for corrosion and wear applications, as well as near-net shaped components [1]. Thick titanium layers (up to several millimeters) can be deposited with a high deposition efficiency using the available state-of-the-art technology [2]. Optimal deposition parameters allow researchers to obtain titanium coating with enhanced mechanical properties, in terms of bond strength, hardness, and tensile strength [2-5]. Within this scenario, particular interest has been gained by the production of titanium coatings by cold spray technique on aluminum substrates providing an advantageous trade-off between the enhanced superficial properties of titanium and the low production cost of the aluminum components [6]. The reasons for this have to be sought in that the most widely used alloys in the aeronautics industry (e.g., the aluminum alloys series 2000 and 7000, especially) are heat-treatable and age-hardened. Therefore, cold spray is more suitable to deposit titanium on aluminum alloy substrates avoiding overcoming the aging temperature than other thermal spray deposition technologies. However, to date it is still difficult to achieve a pore-free microstructure in cold sprayed titanium [1,7]. The relative high residual porosity, from approximately $9 \%$ up to $20 \%$, depending on the process parameters adopted during the depositions [2,4,7-9], negatively affects the final quality of the titanium deposit. Surface hardness and tensile strength of the deposit show a wide range of values from 150 to $300 \mathrm{HV}$ and from 100 to $800 \mathrm{MPa}$, respectively, depending on the porosity level [1]. In addition, the titanium coating showed low tribological properties and reduced corrosion resistance if compared to the bulk titanium [10]. Post-deposition treatments were successfully used to modify the microstructure, reduce the porosity level, and improve the properties of the cold-sprayed titanium. Zahiri et al. [11] first investigated the effect of annealing post treatment on cold-sprayed titanium. They observed a reduction in the amount of macro-pores within the deposit due to the formation of metallurgical bonds between the particles and the elimination of the particle-particle interface, and reported an improvement in the 
ductility due to the grain growth. On the other hand, the annealing resulted in a reduction of the tensile strength of approximately $25 \%$ compared to the as-sprayed titanium and the formation of micro-pores. Vacuum treatment was also investigated by Hussain et al. [7] to reduce the porosity level. The authors found that the heat treatment was able to reduce the volume percentage of macro- and micro-pores by approximately $80 \%$ and $60 \%$, respectively. However, these treatments involve the heating of the whole coating-substrate system, and usually employ relatively high temperatures that are not suitable in the case of aluminum alloy substrates, which require a more selective heating treatment technique. In this regard, laser surface processing (e.g., melting, cladding, alloying, and surface hardening) represents a suitable solution to deal with this issue thanks to its highly localized heat input and high-energy density, which allow for the melting of the surface with a reduced penetration depth $[12,13]$. Marrocco et al. [8] demonstrated that post-deposition laser treatment on titanium coating eliminates the residual micro-porosity and forms a high-quality corrosion barrier layer without any deleterious effect on the substrate.

The authors' previous studies assessed the effectiveness of the laser treatment to promote the formation of a compact layer of titanium dioxide on cold-sprayed titanium coating without affecting the temper state of the aluminum substrate [14,15]. The results of the experimental analysis demonstrated the key role played by the aluminum substrate and the ratio between the coating and substrate thickness (also called thickness ratio, TR). Indeed, once the heat input provided by the laser source is fixed, the temperature is governed by the cooling action exerted by the aluminum substrate being more conductive than the titanium [14,16]. Thermal analysis of the laser surface processing pointed out that the peak temperature experienced by the surface and the cooling rate significantly influenced the formation of titanium oxides with good mechanical and wear properties and a satisfactory adhesion with the underlying untreated coating $[8,14,16,17]$. In addition, the thermal model developed in the previous investigation was able to predict the formation of distinct microstructures inside the coating, pointing out a tight correlation between the estimated temperature fields and the developed metallurgical zones. Indeed, the rutile layer was produced on the irradiated surface, and below this region other different structures of titanium oxides were formed due to oxygen diffusion from the surface inside the titanium. Moving to the interface between the coating and substrate, thermal-induced microstructural evolutions were observed up to the as-deposited titanium (also called base material) which did not experience any modifications [15]. On the other hand, the high temperatures required to promote the proper reaction between the oxygen and the titanium, as well as the characteristics of the laser processing (e.g., high energy density as well as localized heat input) make it difficult to assess the optimal process parameters window. Indeed, experimental investigation revealed how the mismatching between the process parameter led to different adverse results, from ineffective treatment, where the conditions required for the formation of the rutile layer have not been accomplished, to damage to the processed specimen $[14,16]$. The experimental and numerical analyses also showed that the damaging of surface specimens could occur through two distinct phenomena: material loss from the irradiated surface with the subsequent formation of spherical craters along the treated track, and the formation of cracks inside the oxidized layer and at the interface between the hard oxide and the metal. Despite the thermal model proving to be capable of predicting the thermal-induced modifications, it was not able to deal with the occurrence of cracking or the material loss observed in the damaged specimens.

The aim of the present manuscript was to investigate the main causes of the occurrence of the two damage modes, and to achieve a better understanding of the behavior of the cold-sprayed titanium when processed by a laser treatment. To accomplish this, a thermo-mechanical finite element model of the laser treatment was implemented to estimate both thermal and stress fields developed within the deposited coating. The transient temperature field from the thermal analysis due to the laser beam with the boundary conditions was then applied as input thermal loads for the subsequent stress-strain analysis. Numerical outcomes highlighted the relevance of thermal gradients and thermally-induced stresses and strains in promoting the damage of the coating. In particular, a significant role has been 
played by residual tensile stresses that promoted the detaching of the titanium particles causing the formation of deep cracks inside the coating.

\section{Materials and Methods}

The cold spray titanium coating laser post-treatment used as benchmark in the present study has been experimentally investigated by the authors, and the results are detailed in References $[10,14,16]$. In order to give a brief statement of the main points, cold spray laboratory equipment was used to realize grade II titanium coatings, starting from particles with a mean size of $40 \mu \mathrm{m}$. Helium was employed as carrier gas to avoid titanium particles' oxidation during the cold-spray deposition process, ensuring the optimal compaction of the powders. Particles were sprayed at a velocity of $680 \mathrm{~m} / \mathrm{s}$, setting helium gas temperature as $873 \mathrm{~K}\left(600^{\circ} \mathrm{C}\right)$, and chamber pressure at around 12 bars. Two different titanium coatings, 0.4 and $2 \mathrm{~mm}$ thick, respectively, were deposited onto AA2024-T3 $2 \mathrm{~mm}$ thick plates. The chemical composition and the main properties of both grade 2 titanium and AA2024 are available in literature and are not reported here in the interest of brevity $[18,19]$. Three distinct coating-substrate systems were prepared and investigated: the former consists of only the $2 \mathrm{~mm}$ thick titanium deposit, obtained by detaching the coating from the substrate, and the latter two consist of coating-plus-substrate systems, with coating thickness of 2 and $0.4 \mathrm{~mm}$, respectively. Laser post-deposition treatments were carried out using a $200 \mathrm{~W}$ diode laser. Laser source feed rate values of $12.5,200$, and $1000 \mathrm{~mm} / \mathrm{min}$ were employed for each test case.

In the present work, a coupled thermo-mechanical model was used to analyze both the temperature and the stress fields within the titanium coating. A non-linear transient thermal analysis was primarily performed to estimate the temperature history occurring during the laser treatment. A transient structural analysis was then carried out, applying the temperatures obtained for the previous thermal simulation as thermal loads for the mechanical analysis. Figure 1a shows the schematic representation of the laser surface treatment on a plate-shaped titanium deposit. The computational domain consists of a $50 \times 30 \mathrm{~mm}^{2}$ plate. The thickness of the plate was varied according to the test cases considered for the analysis (as described in what follows). The laser irradiated the surface of the coating, which is considered a moving heat source for the 3D model (Figure 1a,b).

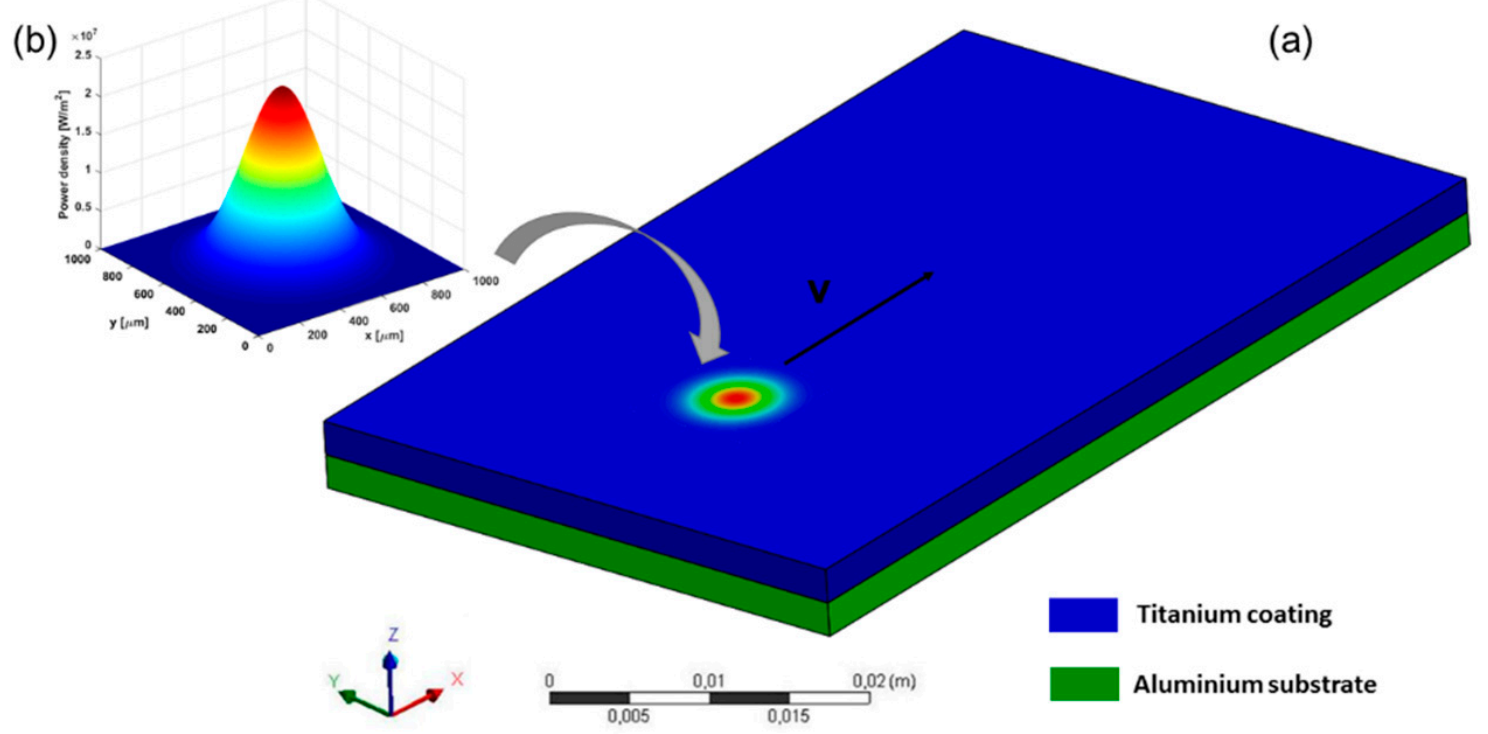

Figure 1. (a) 3D numerical model and (b) Gaussian laser distribution. 


\subsection{Mathematical Formulation}

For the thermal analysis of laser surface treatment, the governing equation is based on the 1st law of thermodynamics and the Fourier heat conduction equation [20-22]. In this study, the heat generation inside the sample related to the deformation energy and chemical reaction was assumed negligible in comparison with the laser heat input. Neglecting also the velocity terms, the thermal equilibrium equation for an isotropic material can be rewritten in the following form:

$$
\rho c \frac{\partial T}{\partial t}=\frac{\partial}{\partial x}\left(k \frac{\partial T}{\partial x}\right)+\frac{\partial}{\partial y}\left(k \frac{\partial T}{\partial y}\right)+\frac{\partial}{\partial z}\left(k \frac{\partial T}{\partial z}\right)
$$

where $\varrho$ is the material density $\left(\mathrm{kg} / \mathrm{m}^{3}\right) ; c$ is the specific heat capacity $(\mathrm{J} / \mathrm{kg} \cdot \mathrm{K}) ; T$ is the temperature; and $k$ is the thermal conductivity $(\mathrm{W} / \mathrm{m} \cdot \mathrm{K})$. All properties of the titanium coating were assumed temperature dependent, conversely physical and thermal properties for the aluminum substrate were set as constant. Considering the significant compaction of the powder after the deposition process and the preparation of the surface [14], the titanium coating was assumed as a bulk material; therefore, the influence of residual porosity was neglected. The heat flux was applied on the external surface of the irradiate elements. The initial condition of uniform temperature distribution throughout the computational domain (both coating and substrate) prior to the laser treatment was assumed:

$$
T(x, y, z)=T_{0}(x, y, z)
$$

where $T_{0}$ is the room temperature taken as $293.15 \mathrm{~K}\left(20^{\circ} \mathrm{C}\right)$. The heat flux on the irradiated surface was given as:

$$
-k\left[\frac{\partial T}{\partial z}\right]=Q_{\text {laser }}-h\left(T_{0}-T\right)
$$

where $h$ is the convective heat transfer coefficient assumed equal to $10 \mathrm{~W} / \mathrm{m}^{2} \cdot \mathrm{K}$ for all the surfaces in the numerical model (i.e., coating layer and substrate) and $T$ is the surface temperature. The $Q_{\text {laser }}$ is the heat flux from the laser beam applied on the coating. The Gaussian model is the most widely adopted profile of a laser beam, using a symmetrical distribution of the laser irradiation across its field domain $[23,24]$, therefore the heat flux distribution can be expressed as:

$$
Q_{\text {laser }}(r)=\frac{A P}{\pi R^{2}} \mathrm{e}^{-\frac{2 r^{2}}{R^{2}}}
$$

where $A$ is the absorptivity of the titanium; $r$ is the radial distance from the heat source center (that varies with time depending on the laser scan speed v considered); $P$ is the laser power; and $R$ is the radius of the laser beam set equal to $1.5 \mathrm{~mm}$. The heat loss due to the radiation has been ignored, considering the short time duration of the laser irradiation. Finally, convective boundary conditions were imposed on the remaining sheet surfaces and a conservative flux condition was applied at the interface between the titanium coating and the aluminum substrate. In the thermal model, the temperature range was obtained by the laser treatment simulation which was simulated by an iterative function that simulates the progress of the laser source along the surface. After the laser treatment, the cooling takes place in air, and for this reason this cooling condition has been used for the simulation. The laser source speed $v$ was varied for each of the simulated conditions.

The high heat flux of the laser beam, coupled with relative short interaction with the surface, causes a significant cooling rate after the laser beam has moved on. The heating and the cooling due to the large temperature gradient experienced between the heated zone and the underlying cold material layer develops residual stress inside the coating [25]. The temperature gradient and the material induced strains in the system are expressed as:

$$
\varepsilon^{t o t a l}=\varepsilon^{e l}+\varepsilon^{t h}
$$


where the total strain $\varepsilon^{\text {total }}$ is a combination of thermal $\left(\varepsilon^{\text {th }}\right)$ and elastic $\left(\varepsilon^{e l}\right)$ strains. Thermal strain is related to the thermal load applied on the material and calculated using the thermal expansion coefficient $(\alpha)$ and the temperature gradient. A typical component of the thermal strain can be given by:

$$
\varepsilon^{\text {th }}=\alpha(\Delta T)
$$

The elastic strain follows Hook's law [26]:

$$
\{\sigma\}=[D]\left\{\varepsilon^{e l}\right\}
$$

Combining Equations (5)-(7) the stress-strain relationship for isotropic material can be expressed as $[27,28]$ :

$$
\begin{aligned}
\varepsilon_{x x} & =\frac{1}{E}\left[\sigma_{x x}+v\left(\sigma_{y y}+\sigma_{z z}\right)\right]+\alpha(\Delta T) \\
\varepsilon_{y y} & =\frac{1}{E}\left[\sigma_{y y}+v\left(\sigma_{x x}+\sigma_{z z}\right)\right]+\alpha(\Delta T) \\
\varepsilon_{z z} & =\frac{1}{E}\left[\sigma_{z z}+v\left(\sigma_{y y}+\sigma_{x x}\right)\right]+\alpha(\Delta T)
\end{aligned}
$$

where $E$ and $v$ are Young's modulus and Poisson's ratio, respectively, $\Delta T$ is the temperature gradient at the point $P(x, y, z)$ in the material and at time $t$.

Table 1 lists the thermo-physical properties adopted for both substrate and coating materials according to material property database $[18,19]$. Temperature-dependent properties were used for the titanium and they have been input prior to the analysis (see Table 1). Young's modulus, Poisson's ratio, yield strength, and shear modulus were also required for the stress analysis. Figure 2 shows

\begin{tabular}{|c|c|c|c|c|c|c|c|c|}
\hline \multirow{2}{*}{ Property } & \multirow{2}{*}{$\begin{array}{l}\text { Aluminum } \\
\text { AA2024-T3 }\end{array}$} & \multicolumn{7}{|c|}{ Titanium Grade II } \\
\hline & & $20^{\circ} \mathrm{C}$ & $100^{\circ} \mathrm{C}$ & $200^{\circ} \mathrm{C}$ & $400{ }^{\circ} \mathrm{C}$ & $600{ }^{\circ} \mathrm{C}$ & $800^{\circ} \mathrm{C}$ & $1000^{\circ} \mathrm{C}$ \\
\hline Density $\left(\mathrm{kg} \cdot \mathrm{m}^{-3}\right)$ & 2780 & & & & 4500 & & & \\
\hline Specific heat capacity $\left(\mathrm{J} \cdot \mathrm{kg}^{-1} \cdot \mathrm{K}^{-1}\right)$ & 921 & 540 & 540 & 540 & 540 & 540 & 540 & 540 \\
\hline Thermal conductivity $\left(\mathrm{W} \cdot \mathrm{m}^{-1} \cdot \mathrm{K}^{-1}\right)$ & 121.8 & 16.3 & 16.3 & 16.3 & 16.3 & 16.3 & 16.3 & 16.3 \\
\hline Coefficient of thermal expansion $\times 10^{-6}\left(\mathrm{~K}^{-1}\right)$ & 23.5 & 8.60 & 8.76 & 8.97 & 9.29 & 9.50 & 9.70 & 9.86 \\
\hline
\end{tabular}
the influence of the temperature on the mechanical properties of titanium. Table 2 summarizes the mechanical properties of aluminum alloy 2024-T3, assumed constant during the laser treatment.

Table 1. Thermo-physical properties of aluminum substrate and titanium coating properties of both materials.

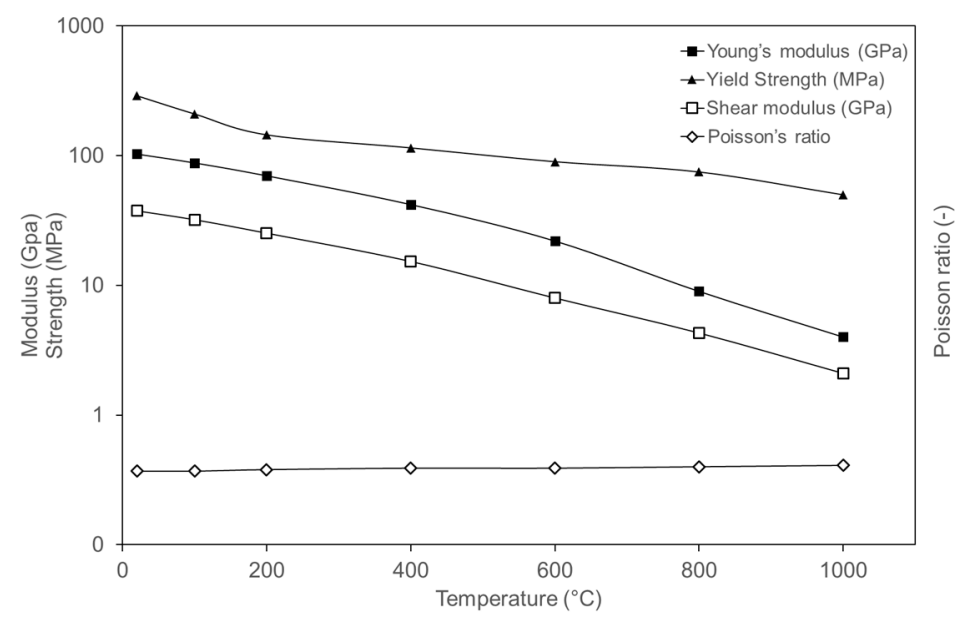

Figure 2. Temperature dependent mechanical properties of titanium coating. 
Table 2. Mechanical properties of Aluminum Alloy AA2024-T3.

\begin{tabular}{cccc}
\hline Yield Strength (MPa) & Young's Modulus (GPa) & Shear Modulus (GPa) & Poisson's Ratio \\
\hline 345 & 73 & 27.5 & 0.33 \\
\hline
\end{tabular}

Noticeable differences characterizing the adopted materials in terms of heat transfer by conduction, as well as thermal expansion represent the key points of the structural effects considering the rigid connection between the substrate and the coating.

\subsection{Numerical Formulation}

In this section, the developed numerical approach is described. The procedure is constituted by three consecutive steps (see Figure 3):

- Creation of the finite element model to perform the thermal simulation of the laser treatment;

- Definition of the temperature distribution, boundary and contact constraints as input for transient structural simulation are here defined;

- Analysis of stress-strain effects useful to evaluate coating damage.

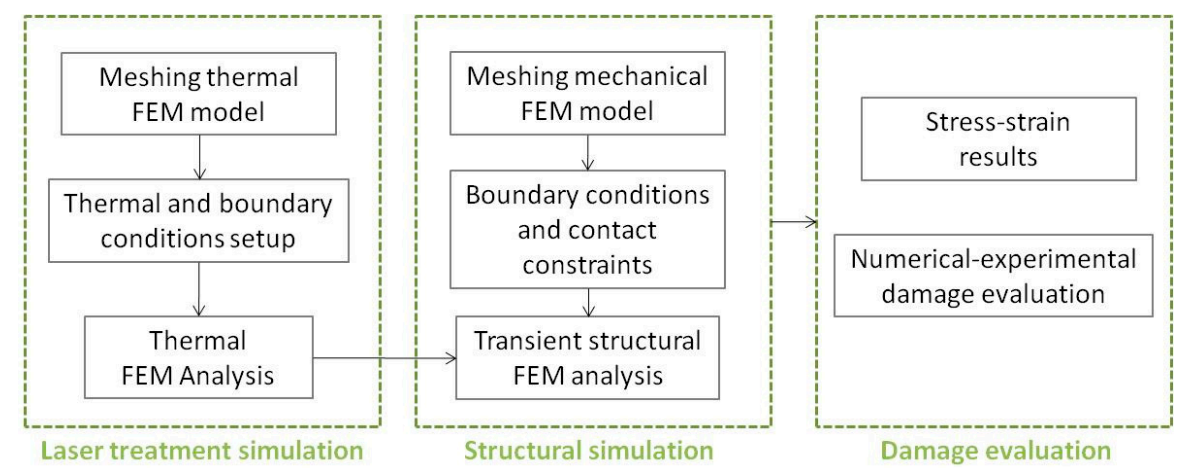

Figure 3. Flowchart of the proposed finite element model (FEM) procedure.

The ANSYS APDL 17.1 commercial finite element package was used to perform the coupled thermo-mechanical analysis for both heat and stress analysis. In the coupling procedure, the temperature history resulting from the thermal analysis, together with boundary and contact constraints imposed into the mechanical model, were adopted as input for the structural simulation. Two different element types were used for the structural and the thermal model. The element used in the thermal model had 1 degree of freedom for the temperature, and the element used for the structural model had 3 degrees of freedom, (i.e., the translations along $x, y$ and $z$ directions). For the structural model, constraint conditions were adopted, as reported in Figure 4, to simulate the plate support conditions during the laser treatment. Moreover, contact elements between the substrate and the coating were used to simulate the "bonded" connections between the two parts. Non-linear transient structural analysis was performed, so the stress-strain was analyzed and compared with those of the damage conditions observed experimentally.

Different computational domains were designed to describe the heat balance within the titanium layer depending on the test cases modeled (Table 3 summarizes the addressed case studies). In the absence of aluminum substrate (Case A), only the coating material was modeled, for the remaining two cases (i.e., Cases B and C) the domain was extended to include also the aluminum substrate. Table 4 summarizes other parameters used in the coupled thermo-structural simulation. 


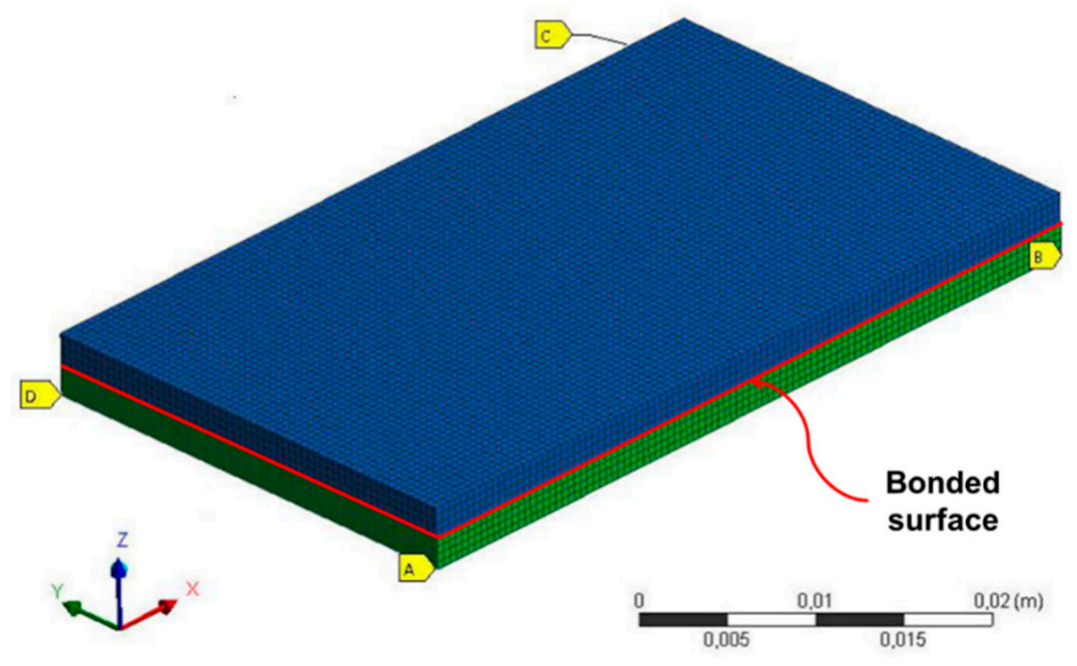

Figure 4. Structural meshed model of the coating-substrate system for the thermo-mechanical analysis.

Table 3. Case studies designation.

\begin{tabular}{ccccc}
\hline Test Case & A & B & C & Domain \\
\hline Coating Thickness (mm) & 2 & 2 & 0.4 & Coating \\
Substrate Thickness (AA 2024-T3) $(\mathrm{mm})$ & 0 & 2 & 2 & Coating + substrate \\
Thickness Ratio & $>>1$ & 1 & $<<1$ & \\
\hline
\end{tabular}

Table 4. Simulation parameters.

\begin{tabular}{cc}
\hline Parameter & Value \\
\hline Laser power, $P$ & $200 \mathrm{~W}$ \\
Scan speed, $v$ (Linear heat input) & $12.5,200,1000 \mathrm{~mm} / \mathrm{min}(1056,66,13.2 \mathrm{~kJ} / \mathrm{m})$ \\
Scan length, $L$ & $30 \mathrm{~mm}$ \\
Laser spot diameter, $D$ & $1.5 \mathrm{~mm}$ \\
\hline
\end{tabular}

\section{Results and Discussions}

The main challenge of the proposed laser treatment is to promote the formation of rutile titanium dioxide on the surface of the coating with improved mechanical properties and good adhesion with the underlying cold-sprayed titanium. To accomplish this, a temperature of approximately $500{ }^{\circ} \mathrm{C}$ should be reached on the titanium surface [29]. The experimental analysis of the treated specimens highlighted the occurrence of four possible scenarios $[14,16]$ : acceptable treatment, ineffective treatment, material loss, and cracking. The laser treatment was defined "Acceptable" when evidence of the formation of a compact rutile layer on the surface of the coating was found. "Ineffective" treatment was obtained in all cases when a too high laser speed (i.e., $1000 \mathrm{~mm} / \mathrm{min}$ ) was adopted. In this instance, the heat input from the laser beam turned out to be inadequate to promote the formation of a stable oxidized layer. Finally, two distinct cases of coating damage were observed. In the former, the damage occurred as a "Material loss" onto the treated surface, resulting in clear macro-porosities and craters on the irradiated surface; in the latter, crack evidence was found along the surface and through the thickness of the coating, suggesting the excessive tendency to catastrophic failure. The analysis reported in the present manuscript was focused on the stress-strain conditions established during the treatment to investigate the causes of the experimentally observed coating damage. In the present study, the results of numerical simulations relative to the "Ineffective treatment" test cases (i.e., Cases A, B, and C at $1000 \mathrm{~mm} / \mathrm{min}$ of scan speed) were excluded for the sake of brevity. All details concerning both numerical and experimental analysis of these samples are available elsewhere $[14,16]$. 
Numerical outcomes of the thermal model [16] evidenced the role played by the coating thickness and the aluminum substrate on the temperature peaks observed on the surface (see Figure 5). Indeed, the aluminum substrate acts like a heat sink drawing the heat from the titanium coating due to the higher thermal conductivity of aluminum influencing the maximum temperatures achieved on the coating surface. Therefore, the absence of substrate caused in the Case A at $12.5 \mathrm{~mm} / \mathrm{min}$ a less effective heat dissipation, and consequently, the highest temperature peak of approximately $1100{ }^{\circ} \mathrm{C}$. Conversely, Cases B and C at the same velocity experience much lower temperature of approximately 700 and $600{ }^{\circ} \mathrm{C}$, respectively. The substrate also influences both the heating and the cooling rate of the irradiated surface. Indeed, the temperature profiles of Cases $B$ and $C$ have a narrower shape than Case A, suggesting the occurrence of more severe transient conditions. Indeed, a sharp cooling can be noticed after the laser source has moved away from the observed location. Especially for the test Case C_12.5 (dotted line in Figure 5), the temperature drops quickly form a maximum of $600^{\circ} \mathrm{C}$ to approximately $200{ }^{\circ} \mathrm{C}$ within a few seconds after the peak. A large thermal gradient obviously occurred at that time influencing the development of residual stresses within the coating.

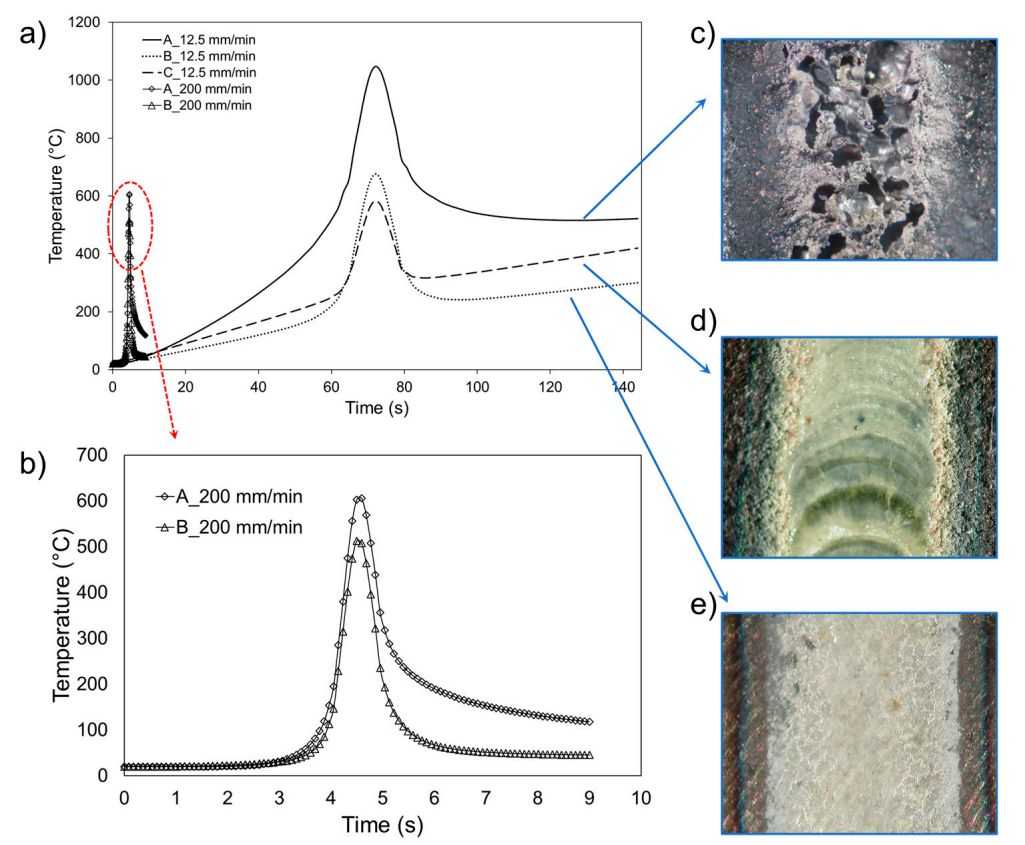

Figure 5. Computed transient temperature profiles: (a) test Cases A, B, and C at $12.5 \mathrm{~mm} / \mathrm{min}$; (b) particularly of test Cases A and B at $200 \mathrm{~mm} / \mathrm{min}$. All profiles were acquired at half length of the laser track at the irradiated surfaces. Surface macrographs of the treated coatings: (c) material loss damage; (d) cracking; (e) effective treatment with homogenous rutile layer.

Figure $5 \mathrm{a}, \mathrm{b}$ also evidence the effect of laser speed on the thermal treatment. As expected, increasing the laser speed (that is reducing the heat input provided to the material) resulted in a decrease in the maximum predicted temperature in both conditions (Cases A and B). The process (i.e., surface heating and cooling) occurred in a very short time compared to the first three tests, resulting in a significant reduction of the heat input provided to the coating. It is worth noting that the presence of the aluminum substrate and its sink effect, fixed the thickness of the titanium coating (equal to $2 \mathrm{~mm}$ for both tests), and played a significant role on the established thermal conditions. Indeed, the small value of the thickness ratio of the configuration $C$ led to a maximum temperature below the threshold value required to produce the rutile layer, on the other hand, test Cases $\mathrm{A}$ and $\mathrm{B}$ experienced higher temperatures, in the range between 600 and $500{ }^{\circ} \mathrm{C}$ (see Figure 5b), allowing the establishment of advantageous conditions for the titanium oxidation $[14,16]$. The results of the thermal analysis pointed out that all the five configurations reported in Figure 5 can potentially be effective to obtain 
the formation of a rutile layer on the coating surface. On the other hand, the thermal analysis was not able to explain the two kinds of failure observed on the specimens [16], therefore the outcomes of the coupled thermo-mechanical presented in the following will be useful to better understand the phenomena which occurred during the laser processing.

The large temperature gradient experienced by the material, and the consequent thermal expansion and contraction during the heating and the cooling stages promoted by the interaction with the laser caused the development of residual stress. The heated material expands, but the surrounding material restrains the movement of the heated part exerting on it a compressive action. During the cooling phase, the contraction and therefore a tensile stress state occurs in the irradiated region, while the material underneath this zone is subjected to a compressive stress field (see Figure 6) [23].

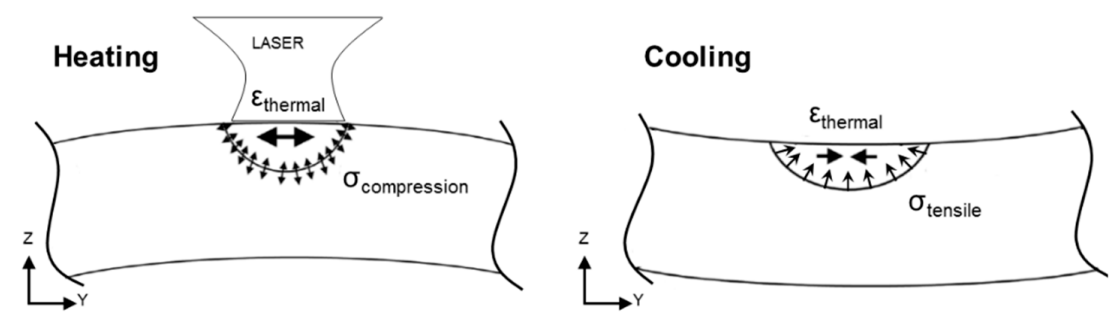

Figure 6. Mechanism of formation of thermal stress and strain induced by the temperature gradient from the laser beam during heating and cooling [23,25].

Figure 7 illustrates the stress and total strain in $Y$ direction (perpendicular to the laser scan direction) on the surface of the coating, where the maximum temperatures were experienced for the test Case A at $12.5 \mathrm{~mm} / \mathrm{min}$ of scan speed. As for the temperature profiles reported in Figure 5, the trends were acquired at the halfway point of the laser path, corresponding to $15 \mathrm{~mm}$ of the track. At the beginning of the treatment, the observed element experienced tensile stresses that reached a maximum value of $20 \mathrm{MPa}$ at $13 \mathrm{~s}$ (Figure $7 \mathrm{~b}$ ). Indeed, the irradiated surface under the heating from the laser beam tended to expand outward depending on the thermal properties of the material, however the surrounding material hinders the expansion and therefore it resulted in being subjected to a tensile action by the heated material. As the laser beam approaches the selected location its temperature starts to rise (Figure 5). The increasing temperature decreases the yield strength of the materials and causes a thermal expansion of the heated metals, consequently a growing in the total strain $\varepsilon_{\text {total }}$ (along the $\mathrm{Y}$ direction) can be observed (Figure 7a). As the laser beam reaches the half length of path, the strain exponentially increases (Figure 7a); however, surrounding low temperature base metal restricts any thermal expansion, which in turn develops compressive strain in the heated metal. Therefore, the material at lower temperature does not allow the heated metal to expand properly causing the arising of compressive stresses at that time (Figure 7a,c). The compressive stress reached the maximum value, approximately equal to $50 \mathrm{MPa}$ at $72 \mathrm{~s}$ of the laser treatment (Figure 7c). As the laser beam crosses the point of interests, the cooling starts and the temperature begins decreasing (Figure 5a). The material shrinks and the total strain progressively reduces. When temperature is still relatively high, the materials can contract without much resistance from the surrounding metal due to the lower yield strength of the materials; however, as the temperature further reduces during the cooling, and the metal recovers its strength, the shrinkage of metal is hindered by the surrounding materials, resulting in the arising of tensile stress acting on the surface (Figure 7d). At the end of the process, the material results to be subjected to a low residual tensile load below $10 \mathrm{MPa}$. 

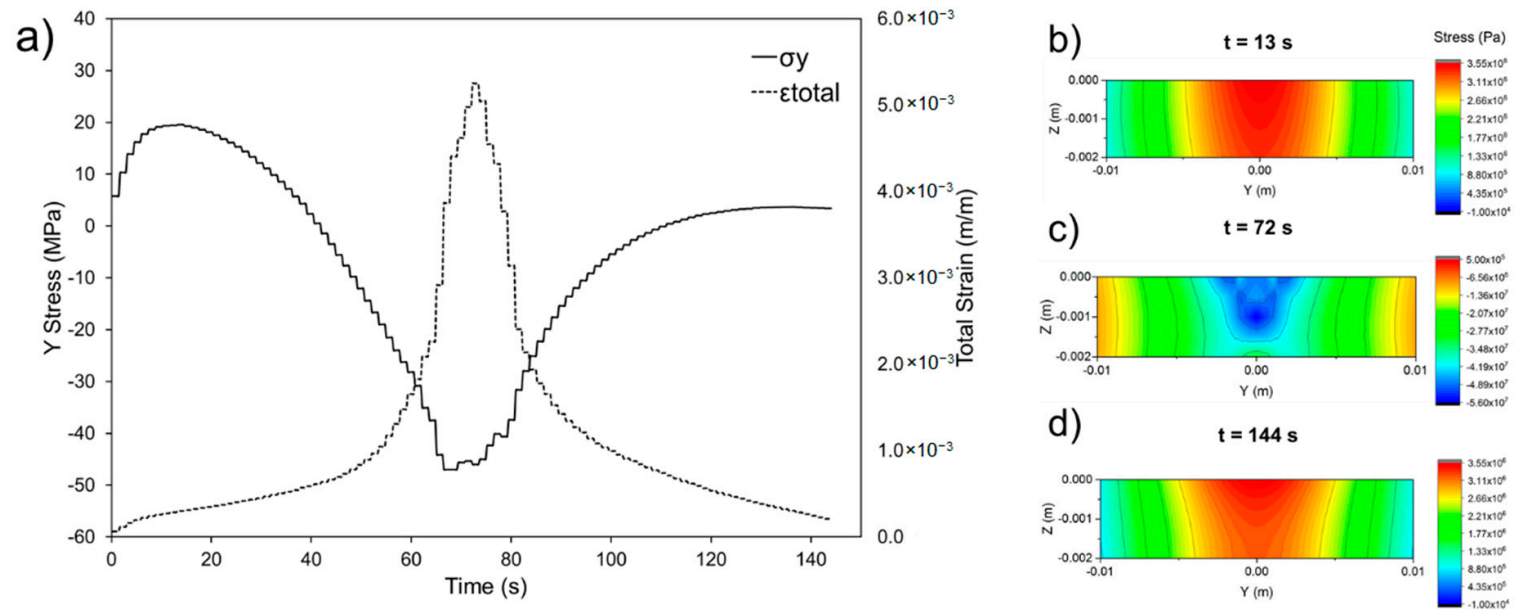

Figure 7. (a) Transient thermal stress and strain profiles in test Case A at laser scan speed of $12.5 \mathrm{~mm} / \mathrm{min}$ : distribution of the stresses within the cross section perpendicular to the laser scan direction at (b) $13 \mathrm{~s}$, (c) $72 \mathrm{~s}$, and (d) $144 \mathrm{~s}$. The tensile compressive stresses are conventionally indicated with the plus and minus signs, respectively.

The tensile or compressive nature of the developed residual stresses, as well as their intensity, are strongly dependent on the thermal gradient experienced by the material (i.e., localized heating and cooling during the heat treatment), and therefore distinct behaviors are expected for the analyzed test cases. Figure 8 reports the distribution of the stresses inside the coating along the laser track for the different cases. The graphs show the profiles of the normal stresses along the $X$ and $Y$ directions at the end of process. A slight variation of the residual stresses inside the track can be observed in all cases moving from the beginning to the end of the track. Indeed, the stresses reduce when the temperature becomes high, close to the region still irradiated by the laser source, due to the reduction of elastic modulus induced by the increased temperature. Consequently, the normal stress attained higher values in the regions initially heated and that were cooling at that time. In almost all test cases stress fields with limited intensity have been developed inside the material. The estimated stresses were in a range between +10 and $-10 \mathrm{MPa}$ for the configuration $\mathrm{A}$ without substrate at both laser scan speeds and for the test Case B_200 (see Figure 8). The stress in the test Case A_12.5 showed a uniform distribution of the stresses both in the $\mathrm{X}$ and $\mathrm{Y}$ directions, with changes in the stress field only in the irradiated region at the end of the track. Conversely, the other two test Cases (i.e., A_200 and B_200) showed a more pronounced variation of the $X$ stress along the laser path (see Figure 8a). The absence of the substrate coupled with the slower laser, indeed, reduced the heat dissipation from the irradiated surface through the underlying deposited titanium to the surrounding ambient at room temperature. The heat concentration led to an average temperature after the peak higher than the latter two configurations (Figure 5a,b), therefore the material experienced a less sharp thermal gradient allowing to attenuate the stress state within the material. For the other two cases, conversely, the higher speed of the laser beam led to narrower temperature profiles and faster cooling than the Case A_12.5 test case (Figure $5 b$ ) that caused the observed variation in the stress. This phenomenon is clearer in the test Case B_200 where a more effective heat dissipation took place due to the presence of the aluminum substrate. Nonetheless, observing the equivalent Von Mises stresses (Figure 9), that describe the overall stress state inside the material and can be used as effective indicator to understand the crack formation [30], the surface in the observed tests experienced values between 10 and $20 \mathrm{MPa}$, far below the elastic limit of the materials. Therefore, no crack formation is expected, as confirmed by the experimental data $[14,16]$. 


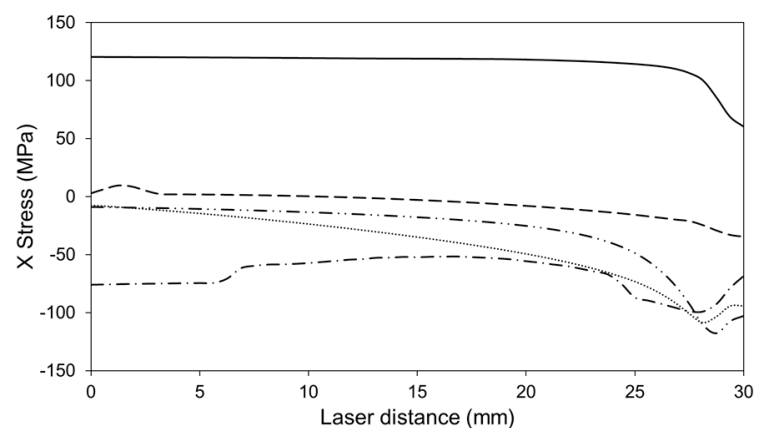

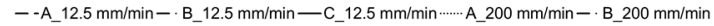

(a)

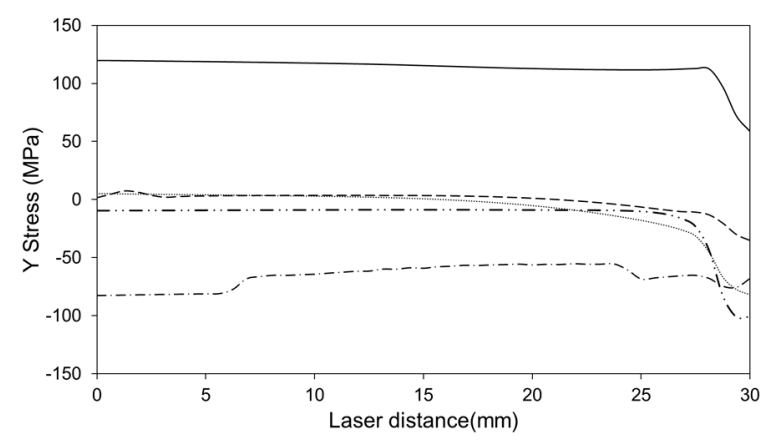

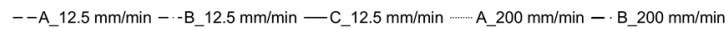

(b)

Figure 8. Distributions of stresses along the parallel $(\mathrm{X})$ and perpendicular $(\mathrm{Y})$ directions to laser scan direction with the laser track distance for the different test cases at the end of the process (see Tables 3 and 4): (a) Normal X stress; (b) Normal Y stress. The profiles have been acquired at the end of the process when the laser focal point is at the limit of the path.

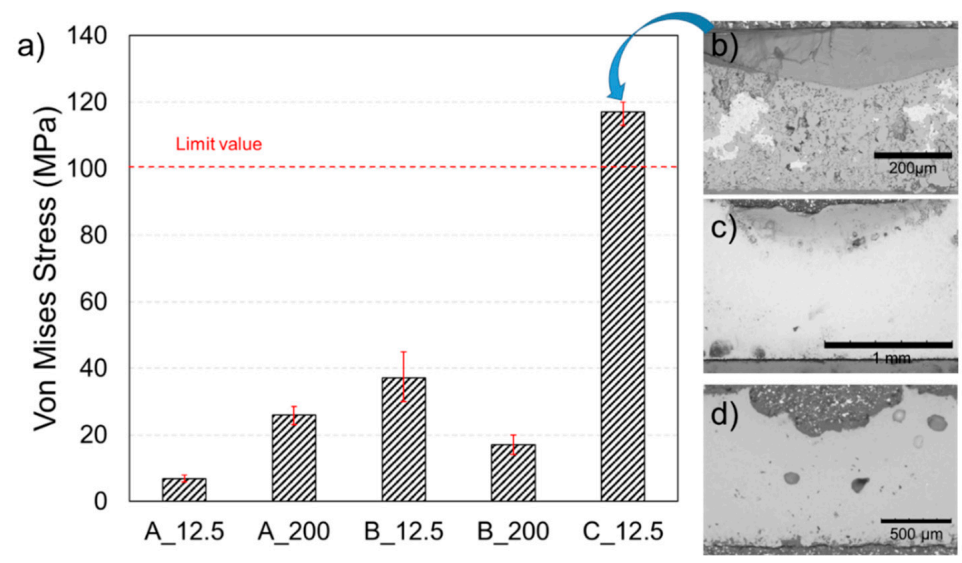

Figure 9. (a) Von Mises stress for the different process configuration (residual internal porosity and the amount of oxygen inside the coating lower the elastic limit of the bulk titanium $(\approx 290 \mathrm{MPa})$ ). Micrographies of the treated coatings cross section: (b) cracking-C_12.5; (c) effective treatment-B_12.5; (d) material loss-A_12.5, A_200 and B_200.

Regarding the test Case B_12.5, the stresses in both $X$ and $Y$ directions on the surface of the coating are mainly compressive and attained values in the range between -60 and $-40 \mathrm{MPa}$ higher than the previous test cases (Figure 8a,b). Tensile stress, approximately equal to $100 \mathrm{MPa}$, have been observed at the interface between the coating and the substrate far from the treated surface, however the stress achieved values below the elastic limit of both material, and also they are balanced by the compressive stresses that usually developed in cold spray deposition (the net stress acting on the component is external stresses + residual stresses). Previous studies [1,31], indeed, showed that the values of the residual stress are strongly dependent on the deposition parameters adopted. In the case of cold spray deposition at low pressure, usually up to 20 bar, and low temperature (in the range between 300 and $600{ }^{\circ} \mathrm{C}$ ) stress values between 0 (or slightly tensile stress) and $-50 \mathrm{MPa}$ were observed. Increasing the process gas temperature and the pressure (e.g., 35 bar and $800{ }^{\circ} \mathrm{C}$ ) resulted in an increasing of the residual stress, which can achieve $-250 \mathrm{MPa}$. The relatively high value of the residual stress observed in the as-deposited titanium coatings, which are higher than the cold-sprayed ductile materials, were mainly due to both the high-yield stress and the high melting temperature that hinder the relaxation of the residual stress arising during the plastic deformation of powders. Therefore, observing the results of the thermo-mechanical analysis on Case B_12.5, it can be argued that the laser 
treatment did not negatively affect the stress state inside the coating that kept a good inter-particle cohesion. Experimental observations $[14,16]$ pointed out also the good cohesion between the deposited titanium powders and between the coating and the aluminum plate (see Figure 9c), suggesting that this configuration allows it to perform an acceptable treatment promoting the formation of the rutile layer without affecting the structural integrity of the coating.

For the test Case C_12.5, internal damages were observed in the coating due to the combined effect of the high heat input provided by the slower laser source and the low thickness of the coating $[14,16]$. The laser treatment on the coating resulted in the formation of a dense and thick oxide layer, similarly to what occurred in the configuration Case B_12.5 (Figure 9b,c); however, the larger thermal gradient, promoted by the reduced value of the thickness ratio between coating and substrate, and the disproportion of the oxide layer size with the coating thickness, caused the formation of cracks inside the layer and a worst cohesion with the underlying materials. Significant tensile stresses in $X$ and $Y$ directions developed on the surface of the coating during the laser treatment. Both stresses attained values approximately equal to +120 MPa and were evenly distributed along the laser path (see Figure 8). The stresses slightly reduced in proximity of the laser source at the end of the track. The absorption of the laser energy by the localized surface of the workpiece, enhanced by the heat sink action exerted by the aluminum substrate, led to larger temperature gradients observed in the coating during the whole treatment promoting then the formation of the tensile stress state. The stresses observed in the treated track (see Figures 7 and 8) are significantly higher than those observed in the other test cases. This is in good agreement with the experimental results that evidenced the occurrence of thermal-induced cracks inside the coating (see Figure 9b) $[14,16]$. Differently from the compressive residual stresses that reduced the failure tendency of the material, the presence of tensile stresses increased the failure tendency due to the increasing of the net stress acting on the surface under an external tensile load, and promoted thus the nucleation of the crack and their propagation inside the material. Therefore, it is important to pay attention to the tensile stress distribution inside the workpiece when addressing with the thermal cracking. A primary approach to a qualitative evaluation of the risks of formation of thermal-induced cracks is comparing the computed equivalent Von Mises stress with the material strength, which could be an indicator of crack formation on the workpiece surface [32,33]. For the Case C_12.5, the thermo-mechanical analysis reported a value of the Von Mises stress close to $120 \mathrm{MPa}$ (Figure 9), which is lower than the yield strength usually adopted for the bulk titanium, (i.e., $290 \mathrm{MPa}$ ) (see Figure 2). However, the values of yield strength of the cold-sprayed titanium deposits were extremely variable depending on the process parameters adopted, the amount of residual porosity inside the coating, as well as the oxygen and nitrogen contents in the deposit [1]. On one side, high gas pressure and temperature coupled with usage of helium or nitrogen as carrier gas instead of air enhanced the mechanical properties of the bulk titanium. Indeed, literature data reported for cold-sprayed titanium deposited using a gas temperature between 800 and $1000{ }^{\circ} \mathrm{C}$, and pressure set equal to 40 bar values of tensile strength that range between 250 and $450 \mathrm{MPa}$ up to $800 \mathrm{MPa}[11,34,35]$. On the other hand, the mechanical properties were strongly sensitive to the oxide inclusions and the inter-particle porosity, which weakened cohesion of the particles affecting the quality of the cold-sprayed deposit. Previous studies reported that an increase of porosity level from $0.1 \%$ to $1 \%$ could result in a reduction in the tensile strength of half of the value of the bulk material. Indeed, values of approximately $100 \mathrm{MPa}$ of tensile strength was measured in deposits with high levels of defect and porosity [36]. Generally speaking, the final porosity in the titanium cold spray deposit depends on different factors, (e.g., particle velocity and temperature and ductility of particles during the deposition); the porosity observed in the titanium deposit can vary over a wide range between the $20 \%$ and $0.1 \%$. Using a high-pressure cold spray (H.P.C.S.) apparatus, porosity of less than $1 \%$ has been achieved $[3,5,31,37,38]$. Conversely, the usage of less severe process conditions, with reduced value of gas temperature and pressure, e.g., 20 bar as maximum pressure and temperature between 300 and $600{ }^{\circ} \mathrm{C}$ (that are typical in the low-pressure cold spray process (L.P.C.S.)), result in values of porosity that range from above the $2 \%-11 \%$, that is higher than the values of other cold sprayed materials like 
copper or aluminum $[2,3,7,39]$. The process parameters adopted for the deposition of the titanium coatings here analyzed and the results of the microstructural and chemical analysis and the mechanical characterization on the as-deposited titanium (the details can be found in $[10,14,16])$ suggest that a tensile strength of the coating of approximately $100 \mathrm{MPa}$ can be used as limit value. As can be argued by the data reported in Figures 7 and 8, the stress state estimated in the Case C_12.5 overcomes the limit of the titanium coating and therefore favorable conditions to the nucleation and propagation of thermal-induced cracks inside the coating can be established. Therefore, the thermo-mechanical model provided results consistent with the experimental observations regarding the cracking damage detected in the tests Case C_12.5 (see Figure 9b)). However, it was not able to provide an exhaustive explanation of the material loss damage observed in the other configurations (see Figure 9d). The reason for that kind of damage has to be looked for in the mechanism of formation of the rutile.

As previously stated, the thermal oxidation of the titanium under specific conditions leads to the formation of oxide layers with different structures (e.g., rutile, anatase or other suboxides) with improved hardness, fatigue, and wear resistance. The nature, compositions, and extension of the surface oxides on the titanium deposit is strictly related to the environmental conditions. High temperatures during the oxidation in a moist environment promotes the formation of the rutile oxide, which is the crystalline form of the $\mathrm{TiO}_{2}$. Conversely, lower temperature produces amorphous structures (e.g., anatase, suboxides $\left(\mathrm{TiO}_{3}\right)$ or a mixture of them) $[40,41]$. The rutile oxide is generally more chemically resistant and thermodynamically stable under the attack of different substance (e.g., $\mathrm{HCl}, \mathrm{H}_{2} \mathrm{SO}_{4}$ or $\mathrm{NaOH})$, and therefore it is the preferable oxide structure to obtain. However, particular attention has to be paid to the processing parameters in order to prevent the delamination of the oxide layer from the underlying titanium due to the mismatch between the harder ceramic layer and the more ductile metal. The conventional thermal oxidation treatments of the titanium follow the steps depicted in Figure 10 [42,43]. First, an oxidation at high temperatures occurs in an oxygen-rich environment at atmospheric pressure or at low oxygen pressure to produce a homogenous oxide layer on the metal surface. The temperatures rule the type of oxide produced. At this stage, temperatures of 600 and $800{ }^{\circ} \mathrm{C}$ are usually adopted. Higher temperature could result in a thick oxide layer having a poor cohesion with the underlying material [43]. Second, a diffusion treatment at higher temperatures (usually the same of the oxidation step) in vacuum condition takes place. During this stage, the atomic oxygen gradually diffuses driven by the steep gradient in the oxygen concentration from the $\mathrm{O}_{2}$-rich layer into the titanium forming an intermediate layer between the oxide and the metal and avoiding the severe stratification (or scaling) of the oxide and ductile metal.

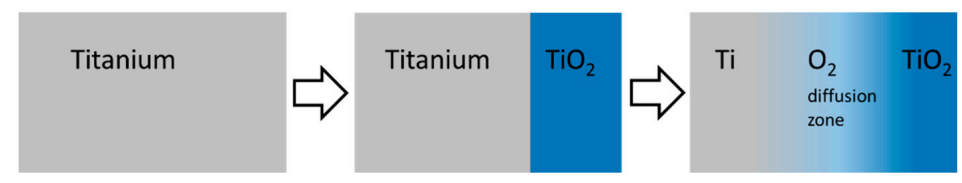

Figure 10. The schematic diagram depicts the oxidation process and the diffusion hardening of the titanium.

In the laser treatment, the oxidation takes place in very short time. Nevertheless, the higher temperatures achievable due to the localized input energy allow the production of an oxide layer. On the other hand, the oxygen diffusion inward of the titanium which usually takes a long time (in the order of hours) is hindered because of the short duration of the laser process. However, the low thermal conductivity of the titanium and the coating thickness, regarding especially the test Cases A and B, reduce the heat dissipation rate, and thus the temperature remains relatively high allowing the oxygen to diffuse into the titanium deposit. Experimental data showed a gradual reduction of the oxygen concentration from the surface to the inner part of the coating, resulting in decreasing hardness of the material $[14,16]$. Conversely, the sharp temperature gradient experienced by the coating for tests Cases A_200 and B_200 caused a too fast decreasing of the temperature inside the material that hindered the diffusion of the $\mathrm{O}_{2}$. A thin oxide layer was produced on the surface of the two samples, however its 
poor cohesion with the underlying metal and the differential thermal expansion of oxide and metal led to a delamination of rutile layer and the expulsion of the particles from the irradiated surface resulting in the observed craters on the treated surface. Regarding the test Case A_12.5, the material loss could be due to the combined effect of the high temperature experienced by the material (see Figure 5) and the high partial oxygen pressure. Indeed, oxidation at high temperature and larger time at that level due the reduced heat dissipation characterizing this sample led to the formation of a thick oxide layer that tend to blister and exfoliate [42]. Treatment at temperature exceeding the $800{ }^{\circ} \mathrm{C}$ and in atmospheric pressure condition can promote the ingress of gases, like hydrogen, that can diffuse quickly aided by the local high temperature resulting in contamination of the surface of the workpiece and thus degradation of the oxide layer produced. Therefore, temperature usually below the $800^{\circ}$ are recommended because of the oxygen form a passivation layer on the surface of the titanium that hinder the diffusion of gases inside the material.

\section{Conclusions}

A three-dimensional model was developed to predict and investigate the temperature and the stress fields inside the titanium coating during surface laser treatment using ANSYS APDL suite. Thermal loads acting as the processed surface have been previously calculated using a thermal model for the interaction between the laser source and the titanium coating. The temperature history was used as input loads of the mechanical model. Transient mechanical analysis was carried out to estimate the thermal-induced stresses inside the material. The results of the analysis can be summarized in the following points:

- Highest predicted temperatures have been observed on the surface of samples processed at lower laser scan speed. The presence of a substrate influences the maximum temperature achieved on the surface as well as the cooling rate experienced by the material.

- Higher scan speed attains reduced value of temperature and material experiences sharper thermal gradients during the heating and cooling. The substrate showed to have a reduced influence on the temperature levels in comparison with the samples treated at lower speed.

- Compressive stresses have been found on the test case with thickness ratio equal to 1 , processed with a laser scan speed of $12.5 \mathrm{~mm} / \mathrm{min}$ (Case B_12.5). Compressive stress field inside the material are beneficial for reducing the failure tendency and enhancing the fatigue endurance of the deposit. Numerical results confirmed the effectiveness of the treatment carried out under this configuration.

- A tensile stress field was observed in the sample with thickness ratio $<1$, adopting $12.5 \mathrm{~mm} / \mathrm{min}$ as laser scan speed (Case C_12.5). High value of the equivalent Von Mises stress was predicted inside the coating due to the sharp thermal gradient and the reduced thickness of the titanium deposit. The stress overcame the tensile strength of the cold-sprayed titanium pointing out the high risk of nucleation and propagation of cracks inside the coating. The numerical results are in good agreement with the experimental observations.

- $\quad$ Reduced tensile stresses were found in the other test cases analyzed. The predicted stress field was too low to cause the formation of cracks inside the material. The mechanical model was not able to explain the occurrence of the observed material loss. This kind of damage can be related to the weakness of the rutile layer produced and the mismatching with the underlying ductile metal.

- The proper matching between the laser heat input and the thickness ratio between the titanium coating and the aluminum substrate play a key role in the laser treatment. Indeed, the ability of the substrate to dissipate the heating from the coating allowed it to obtain the proper temperature distribution inside the coating, avoiding the overheating of the surface or ineffective treatment.

- In case of ratio between the coating and substrate thickness approximately equal to 1 , a higher heat input can be adopted to promote the formation of a compact and dense titanium oxide layer. High laser energy input should be avoided in the case of reduced value of the thickness ratio. 
Indeed, the resulting high temperature gradient could cause the formation of intense residual stress fields inside the coating and the consequent catastrophic failure of the cold spray deposited titanium. For this coating/substrate configuration, lower heat input can be used in case of thin coatings obtaining a thin superficial rutile layer with good adhesion with the underlying coating.

Author Contributions: Conceptualization, A.A.; Methodology, P.C.; Software, P.C.; Validation, A.A. and F.R.; Formal Analysis, P.C. and F.R.; Investigation, F.R. and A.A.; Resources, A.A.; Data Curation, P.C.; Writing-Original Draft Preparation, F.R. and A.A.; Writing-Review \& Editing, P.C., A.A. and F.R.; Visualization, F.R.; Supervision, P.C.

Funding: This research received no external funding.

Conflicts of Interest: The authors confirm that this article has not conflict of interest, financial or otherwise.

\section{References}

1. Hussain, T. Cold spraying of titanium: A review of bonding mechanisms, microstructure and properties. Key Eng. Mater. 2012, 533, 53-90. [CrossRef]

2. Bae, G.; Kumar, S.; Yoon, S.; Kang, K.; Na, H.; Kim, H.-J.; Lee, C. Bonding features and associated mechanisms in kinetic sprayed titanium coatings. Acta Mater. 2009, 57, 5654-5666. [CrossRef]

3. Zahiri, S.H.; Antonio, C.I.; Jahedi, M. Elimination of porosity in directly fabricated titanium via cold gas dynamic spraying. J. Mater. Process. Technol. 2009, 209, 922-929. [CrossRef]

4. Zahiri, S.H.; Mayo, S.C.; Jahedi, M. Characterization of cold spray titanium deposits by X-ray microscopy and microtomography. Microsc. Microanal. 2008, 14, 260-266. [CrossRef] [PubMed]

5. Wong, W.; Rezaeian, A.; Irissou, E.; Legoux, J.G.; Yue, S. Cold spray characteristics of commercially pure Ti and Ti-6Al-4V. Adv. Mater. Res. 2010, 89-91, 639-644. [CrossRef]

6. Boyer, R.R. An overview on the use of titanium in the aerospace industry. Mater. Sci. Eng. A 1996, 213, 103-114. [CrossRef]

7. Hussain, T.; McCartney, D.G.; Shipway, P.H.; Marrocco, T. Corrosion behavior of cold sprayed titanium coatings and free standing deposits. J. Therm. Spray Technol. 2011, 20, 260-274. [CrossRef]

8. Marrocco, T.; Hussain, T.; McCartney, D.G.; Shipway, P.H. Corrosion performance of laser posttreated cold sprayed titanium coatings. J. Therm. Spray Technol. 2011, 20, 909-917. [CrossRef]

9. Pathak, S.; Saha, G. Development of Sustainable cold spray coatings and 3D additive manufacturing components for repair/manufacturing applications: A critical review. Coatings 2017, 7, 122. [CrossRef]

10. Astarita, A.; Rubino, F.; Carlone, P.; Ruggiero, A.; Leone, C.; Genna, S.; Merola, M.; Squillace, A. On the improvement of AA2024 wear properties through the deposition of a cold-sprayed titanium coating. Metals 2016, 6, 185. [CrossRef]

11. Zahiri, S.H.; Fraser, D.; Jahedi, M. Recrystallization of cold spray-fabricated CP titanium structures. J. Therm. Spray Technol. 2009, 18, 16-22. [CrossRef]

12. Steen, W.M.; Mazumder, J. Laser Material Processing; Springer: London, UK, 2010; ISBN 978-1-84996-061-8.

13. Ion, J. Laser Processing of Engineering Materials: Principles, Procedure and Industrial Application, 1st ed.; Elsevier: Boston, MA, USA, 2005; ISBN 9780080492803.

14. Rubino, F.; Astarita, A.; Carlone, P.; Genna, S.; Leone, C.; Memola Capece Minutolo, F.; Squillace, A. Selective laser post-treatment on titanium cold spray coatings. Mater. Manuf. Process. 2016, 31, 1500-1506. [CrossRef]

15. Rubino, F.; Paradiso, V.; Astarita, A.; Carlone, P.; Squillace, A. Advances in titanium on aluminium alloys cold spray coatings. In Cold-Spray Coatings; Springer International Publishing: Cham, Switzerland, 2018; pp. 225-249.

16. Carlone, P.; Astarita, A.; Rubino, F.; Pasquino, N.; Aprea, P. Selective laser treatment on cold-sprayed titanium coatings: Numerical modeling and experimental analysis. Metall. Mater. Trans. B 2016, 47, 3310-3317. [CrossRef]

17. Dong, H.; Bell, T. Enhanced wear resistance of titanium surfaces by a new thermal oxidation treatment. Wear 2000, 238, 131-137. [CrossRef]

18. ASM Specialty Handbook: Aluminum and Aluminum Alloys; Davis, J.R. (Ed.) ASM International: Materials Park, OH, USA, 1993; ISBN 978-0-87170-496-2. 
19. Duncan, R.M.; Hanson, B.H.; Design Council; British Standards Institution; Council of Engineering Institutions. The Selection and Use of Titanium; Oxford University Press for the Design Council, the British Standards Institution, the Council of Engineering Institutions: Oxford, UK, 1980; ISBN 0198591764.

20. De Oliveira, W.P.; Savi, M.A.; Pacheco, P.M.C.L. Finite element method applied to the quenching of steel cylinders using a multi-phase constitutive model. Arch. Appl. Mech. 2013, 83, 1013-1037. [CrossRef]

21. Toyserkani, E.; Khajepour, A.; Corbin, S. 3-D finite element modeling of laser cladding by powder injection: Effects of laser pulse shaping on the process. Opt. Lasers Eng. 2004, 41, 849-867. [CrossRef]

22. Santhanakrishnan, S.; Kong, F.; Kovacevic, R. An experimentally based thermo-kinetic phase transformation model for multi-pass laser heat treatment by using high power direct diode laser. Int. J. Adv. Manuf. Technol. 2013, 64, 219-238. [CrossRef]

23. Roberts, I.A. Investigation of Residual Stresses in the Laser Melting of Metal Powders in Additive Layer Manufacturing. Ph.D. Thesis, University of Wolverhampton, Wolverhampton, UK, September 2012.

24. Hussein, A.; Hao, L.; Yan, C.; Everson, R. Finite element simulation of the temperature and stress fields in single layers built without-support in selective laser melting. Mater. Des. 2013, 52, 638-647. [CrossRef]

25. Kruth, J.P.; Froyen, L.; Van Vaerenbergh, J.; Mercelis, P.; Rombouts, M.; Lauwers, B. Selective laser melting of iron-based powder. J. Mater. Process. Technol. 2004, 149, 616-622. [CrossRef]

26. Kings, T.H.E. "Advanced mechanics of materials” 5th edition, A.P. Boresi, R.J. Schmidt and O.M. Sidebottom. Strain 1993, 29, 141-142. [CrossRef]

27. Luzin, V.; Spencer, K.; Zhang, M.; Matthews, N.; Davis, J.; Saleh, M. Residual stresses in cold spray coatings. In Cold-Spray Coatings; Cavaliere, P., Ed.; Springer International Publishing: Cham, Switzerland, 2018; pp. 451-480.

28. Yin, S.; Suo, X.; Su, J.; Guo, Z.; Liao, H.; Wang, X. Effects of substrate hardness and spray angle on the deposition behavior of cold-sprayed Ti particles. J. Therm. Spray Technol. 2014, 23, 76-83. [CrossRef]

29. Firm, K.; Boyer, R.; Welsch, G. Materials Properties Handbook: Titanium Alloys; ASM International: Materials Park, OH, USA, 1994; ISBN 978-0-87170-481-8.

30. Kabir, I.R.; Yin, D.; Tamanna, N.; Naher, S. Thermomechanical modelling of laser surface glazing for H13 tool steel. Appl. Phys. A 2018, 124, 260. [CrossRef]

31. Gulizia, S.; Aus, C.; Trentin, A.; Veccu, S.; Rech, S.; King, P.C.; Jahedi, M.; Guagliano, M. Microstructure and mechanical properties of cold spray titanium coatings. In Thermal Spray 2010: Global Solutions for Future Application, Proceedings of the International Thermal Spray Conference, Singapore, 3-5 May 2010; Marple, B.R., Agarwal, A., Hyland, M.M., Lau, Y.-C., Li, C.-J., Lima, R.S., Montavon, G., Eds.; Springer: New York, NY, USA, 2010.

32. Larsson, P.-L.; Giannakopoulos, A.E. Tensile stresses and their implication to cracking at pyramid indentation of pressure-sensitive hard metals and ceramics. Mater. Sci. Eng. A 1998, 254, 268-281. [CrossRef]

33. Li, J.F.; Li, L.; Stott, F.H. Thermal stresses and their implication on cracking during laser melting of ceramic materials. Acta Mater. 2004, 52, 4385-4398. [CrossRef]

34. Hussain, T. A Study of Bonding Mechanisms and Corrosion Behaviour of Cold Sprayed Coatings. Ph.D. Thesis, University of Nottingham, Nottingham, UK, 2011.

35. Binder, K.; Gartner, F.; Klassen, T. Ti-parts for aviation industry produced by cold spraying. In Thermal Spray 2010: Global Solutions for Future Applications, Proceedings of the International Thermal Spray Conference, Singapore, 3-5 May 2011; Marple, B.R., Agarwal, A., Hyland, M.M., Lau, Y.-C., Li, C.-J., Lima, R.S., Montavon, G., Eds.; Springer: New York, NY, USA, 2011; p. 380.

36. Blose, R.E. Spray forming titanium alloys using the cold spray process. In Thermal Spray Connects: Exploring Its Surfacing Potential; Lugscheider, E., Ed.; DVS-Verlag: Düsseldorf, Germany, 2005.

37. Rezaeian, A.; Irissou, E.; Chromik, R.; Yue, S. Characterization of cold-sprayed Ni, Ti, Cu coating properties for their optimization. In Thermal Spray: Crossing Borders, Proceedings of the 2008 International Thermal Spray Conference, Maastricht, the Netherlands, 2-4 June 2008; Marple, B.R., Li, C.-J., Hyland, M.M., Lima, R.S., Lau, Y.-C., Montavon, G., Eds.; Springer: New York, NY, USA, 2008; pp. 2-4.

38. Wong, W.; Irissou, E.; Ryabinin, A.N.; Legoux, J.-G.; Yue, S. Influence of helium and nitrogen gases on the properties of cold gas dynamic sprayed pure titanium coatings. J. Therm. Spray Technol. 2011, 20, $213-226$. [CrossRef] 
39. Marrocco, T.; McCartney, D.G.; Shipway, P.H.; Sturgeon, A.J. Production of titanium deposits by cold-gas dynamic spray: Numerical modeling and experimental characterization. J. Therm. Spray Technol. 2006, 15, 263-272. [CrossRef]

40. Dunn, D.; Raghavan, S. Formation and characterization of anodized layers on CP Ti and Ti-6Al-4V biomaterials. Surf. Coat. Technol. 1992, 50, 223-232. [CrossRef]

41. Güleryüz, H.; Çimenoğlu, H. Effect of thermal oxidation on corrosion and corrosion-wear behaviour of a Ti-6Al-4V alloy. Biomaterials 2004, 25, 3325-3333. [CrossRef] [PubMed]

42. Hertl, C.; Werner, E.; Thull, R.; Gbureck, U. Oxygen diffusion hardening of cp-titanium for biomedical applications. Biomed. Mater. 2010, 5, 054104. [CrossRef] [PubMed]

43. Dong, H.; Li, X.Y. Oxygen boost diffusion for the deep-case hardening of titanium alloys. Mater. Sci. Eng. A 2000, 280, 303-310. [CrossRef]

(C) 2018 by the authors. Licensee MDPI, Basel, Switzerland. This article is an open access article distributed under the terms and conditions of the Creative Commons Attribution (CC BY) license (http://creativecommons.org/licenses/by/4.0/). 